\title{
Rural Community Health in Nicaragua: Needs Assessment Results and Self-Reported Health Status
}

\author{
Jennifer H. Caspari ${ }^{1}$, Matthew P. Martin ${ }^{2} \&$ Karen Herrera ${ }^{3}$ \\ ${ }^{1}$ Department of Internal Medicine, University of Nebraska, Omaha, United States of America \\ ${ }^{2}$ College of Health Solutions, Arizona State University, Phoenix, United States of America \\ ${ }^{3}$ Hospital Militar Dr. Alejandro Dávila Bolaños, Managua, Nicaragua \\ Correspondence: Matthew Perry Martin, College of Health Solutions, Arizona State University, 550 N. $3^{\text {rd }}$ Street, \\ Phoenix, AZ, 85004. Tel: 1-602-496-1607.
}

Received: April 15, 2021 Accepted: June 15, 2021 Online Published: June 29, 2021

doi:10.5539/gjhs.v13n8p42 URL: https://doi.org/10.5539/gjhs.v13n8p42

\begin{abstract}
Chronic disease-related burden and deaths are increasingly worldwide. The Latin American country of Nicaragua is no exception. Cardiovascular disease (CVD) is the leading cause of death in Nicaragua and health behaviors, such as sedentary lifestyle and tobacco use, can exacerbate risk associated with CVD. The aims of this study were to identify risk factors and health-promoting behaviors associated with CVD present in three rural communities in Nicaragua. Results from a needs assessment indicated that need assessments that utilize patient-reported outcome measures were feasible to conduct in rural Nicaragua communities, typical CVD risk factors were not prevalent in the rural communities we surveyed, and the overall good health of these communities reflects the perceived health status reported by participants. Findings of this study suggest that community health workers could consider hypertension and diabetes treatment, patient health information on nutrition, healthcare access, and healthy food access as potential target areas to improve community health in Nicaragua.
\end{abstract}

Keywords: rural health, community needs assessment, perceived health status

\section{Introduction}

\subsection{Chronic Disease Prevalence}

Chronic disease-related burden and deaths are increasing worldwide and account for an estimated $71 \%$ of all deaths globally (Global Burden of Disease, 2016). A vast majority of "premature" deaths (between the ages of 30 and 69) from chronic disease occur in low- and middle-income countries. Once thought to be diseases solely of more affluent countries, chronic disease patterns are shifting from wealthier countries to poorer countries and economically disadvantaged groups. Of these chronic disease-related deaths, almost half are due to cardiovascular disease (CVD; 2016). One report shows that $80 \%$ of CVD deaths across the world occur in low-and middle-income countries (Pan American Health Organization [PAHO], 2017).

\subsection{Chronic Disease in Nicaragua}

In Latin America, specifically, CVD occurrence and death rates continue to rise. By 2020, the CVD mortality rate is anticipated to increase by $60 \%$ (Fernando et al., 2014). The Latin American country of Nicaragua is no exception. CVD is the leading cause of death in Nicaragua, accounting for $27 \%$ of all deaths in the country (PAHO, 2017). Risk factors for CVD continue to increase in tandem with CVD rates. These include sedentary lifestyle (Fernando et al., 2014), overweight and obesity rates, violence-rated stress, and tobacco use (PAHO, 2017). Additionally, high rates of hypertension and pre-hypertension, leading CVD risk factors, occur in Nicaraguan populations (Alicea-Planas et al., 2016).

\subsection{Chronic Disease and Health Behaviors}

There is a clear relationship between chronic disease and health behaviors like substance use, eating habits, and physical activity. Moreover, there is compelling evidence of a strong link between chronic health conditions (e.g., cardiovascular disease) and psychosocial factors like job demand, interpersonal conflicts, and mental health (Ducat et al., 2014; Pikhart \& Pikhartova, 2015). Because chronic disease prevention and management often involve multiple risk factors (e.g., health behaviors, psychosocial issues), it is valuable to collect patient-reported 
outcomes (PRO) that are relevant to and actionable by patients and their healthcare providers. PROs (e.g., health-related quality of life, functioning, evaluations of health care, health behaviors) can include information on how patients are experiencing and managing their own health, supplement clinic-generated information (e.g., lab tests, imaging studies, clinic notes), and inform clinical decision-making. However, PROs are rarely collected in clinical practice. The integration of PROs in medical settings improves patient-provider communication, patient care, and health outcomes (Greenhalgh, 2009). In rural communities with limited access to clinic equipment and health information technology, PROs are even more valuable for screening, monitoring, and supporting individuals with chronic diseases.

\subsection{Rural Community Health in Nicaragua}

In Nicaragua, approximately $42.2 \%$ of the population lives in a rural area (United Nationals International Children's Emergency Fund [UNICEF], 2021). Small, rural communities often have access to local health posts at which a healthcare team, including a doctor, nurse, and community health worker, work with the community to mitigate health problems and focus on preventative care. The team travels around the community to gather health information from families (Ministry of Health [MINSA], 2007). Although rural residents receive care through the health post medical team, they often must travel long distances for needed specialty healthcare (Prado et al., 2016). Additionally, rural residents are disproportionately impacted by poverty.

In Nicaragua, poverty is 4.4 times more extreme in rural communities than in urban environments, with 7 out of 10 rural community members experiencing poverty (PAHO, 2007). Poverty is an additional barrier to rural residents receiving needed healthcare, making specialty care visits and transportation to medical centers cost prohibitive. For all the above, Nicaragua continues to struggle with efficiency in health care facilities, especially for impoverishes populations. This lack of access negatively contributes to prevention and screening methods against communicable and non-communicable diseases (Angel-Urdinola et al., 2008). One of the rural areas is the Estelí Department in Nicaragua, which has a population of 205,616 residents with rural residents accounting for 45 percent. This area is composed of six municipalities, including Pueblo Nuevo, Condega, Estelí, San Juan de Limay, La Trinidad, and San Nicolás (Instituto Nacional de Estadística [INEC], 2003).

\subsection{Study Aims}

Because much of the rural population in Nicaragua experience poverty and healthcare access challenges, along with increasingly present risk factors for CVD (e.g., rising obesity rates and tobacco use), it is important to determine which risk factors are health promoters are present in each rural community. Only then can a plan of action aimed at mitigating risk and promoting health be tailored to meet the needs of the community. As such, the aims of this study were to 1) identify risk factors associated with CVD present in three rural communities in Nicaragua and 2) identify health-promoting behaviors associated with mitigating CVD risk present in three rural Nicaraguan communities.

\section{Methods}

\subsection{Study Design}

A cross-sectional needs assessment was conducted using a self-report health measure and the Community-Oriented Primary Care (COPC; S. Kark \& E. Kark, 1999) approach. Inherent in COPC is collaboration with community stakeholders, integrating clinical care and public health, and addressing determinants of health and illness. The term 'health' in this approach refers to comprehensive wellbeing that includes biomedical, behavioral, social, and cultural health, rather than solely the absence or presence of physical illness (J. Gofin \& R. Gofin, 2011). The first step of the COPC's six-step process is to identify the community's characteristics. The second step is to develop an understanding of the health conditions and behaviors that are most impactful for the community. Steps three through six focus on (3) determining which interventions could be most impactful for the most pertinent challenges, (4) delivering the intervention, (5) evaluating the intervention, and then (6) creating a plan to address additional community needs (J. Gofin \& R. Gofin, 2011).

\subsection{Needs Assessment Procedure}

Prior to data collection, we partnered with our Nicaraguan physician collaborator to apply for and receive IRB approval from our United States- based academic institution. Three rural communities in Nicaragua, near the city of Estelí, with whom our Nicaraguan physician partner had previous relationships, were included in the study. Participants were included in the study if they lived in one of the rural communities and were seeking medical supplies or medical care. There were no exclusion criteria. Data collection occurred in 2019, over three days, one for each community, from early morning until late afternoon. The research team split into two smaller teams, each containing one nursing student and two researchers from the United States, a physician from Nicaragua, and either 
a community health worker, or nurse from the local community. Each team provided medical supplies and brief medical testing (e.g., blood pressure, weight) while completing needs assessment surveys with participants. Community members' decision to take part in the research project did not impact their receipt of supplies and medical testing that were being delivered the same day by our team. Participants completed a demographic questionnaire and the My Own Health Report (MOHR) assessment. Survey questions were read aloud to participants by a study team member trained to deliver the needs assessment. No identifying information other than demographic data were collected. Identification numbers were used in lieu of participant names. Completed surveys were kept in a portable locked box.

\subsection{Measures and Analysis}

The My Own Health Report (MOHR) project was developed by the National Institute of Health (NIH), the Agency for Healthcare Research and Quality, and the NIH Office of Behavioral and Social Science Research, in collaboration with several academic institutions. The purpose of the MOHR is to collect and address patient reported measures using the principles of rapid, relevant pragmatic research (Glasgow et al., 2014). It addresses ten domains of health behavior and psychosocial health, including mental health, health behaviors, substance abuse, and quality of life (2014). The initial MOHR trial was conducted among a diverse population, including clinics serving predominantly Spanish-speaking (or Latinx) patients. The feedback and evaluation phases of this study allowed the questionnaire to be adapted culturally to different populations, and more specifically, a Spanish version was adapted to Latinx communities. The Spanish version of the MOHR was adjusted culturally to fit rural Nicaraguan communities with the help of local collaborators. All MOHR survey data were organized and analyzed using descriptive statistics to determine central tendency and variation. A chi-square test for independence was conducted to detect gender differences with health conditions and correlation coefficients were calculated to explore relationships between health conditions, age, health behaviors, and mental health. All analyses were completed using SPSS software (version 26).

\section{Results}

\subsection{Participant Characteristics}

Characteristics for the sample are presented in Table 1. The sample $(n=97)$ included 73 women $(75.3 \%)$ and 23 men $(23.7 \%)$, ranging in age from 19-88 $(M=45.36 ; S D=17.82)$. Most participants reported being married $(n=$ 46; 47.4\%). For employment, 66 (68.0\%) participants reported homemaker, 18 (18.6\%) reported farmer, four (4.1\%) reported teacher, and seven reported various other statuses. Most participants reported some high school (39.2\%), elementary school (13.4\%), or no formal schooling (10.3\%).

Table 1. Demographic Characteristics ( $\mathrm{N}=97)$

\begin{tabular}{ll}
\hline Variable & $\mathbf{4 5 . 3 6} \pm \mathbf{1 7 . 8 2}$ \\
\hline Age & $23(23.7)$ \\
\hline Gender & $73(75.3)$ \\
Wen & \\
\hline Marriage & $46(47.4)$ \\
Married & $1(1.0)$ \\
Divorced & $1(1.0)$ \\
Separated & $5(5.2)$ \\
Widowed & $26(26.8)$ \\
Cohabiting & $18(18.6)$ \\
Single & $4.13 \pm 1.81$ \\
Number of people in home, $M(S D)$ & \\
\hline Employment & $66(68)$ \\
Homemaker & $18(18)$ \\
Farmer & $4(4)$ \\
Teacher & $7(7)$ \\
Other & \\
\hline
\end{tabular}




\section{Education}

Never attended school

$10(10.3)$

Elementary school

13 (13.4)

Some high school

38 (39.2)

High school graduate

$9(9.3)$

Some college or technical school

$11(11.3)$

College graduate

$9(9.3)$

Graduate work or college

$7(7.2)$

\section{Overall Health}

$\begin{array}{ll}\text { Poor } & 6(6.2) \\ \text { Fair } & 8(8.2) \\ \text { Good } & 16(16.5) \\ \text { Very good } & 48(49.5) \\ \text { Excellent } & 19(19.6)\end{array}$

Chronic medical conditions

Hypertension

29 (29.9)

Cholesterol

23 (23.7)

Diabetes

7 (7.2)

At least one condition

22 (22.7)

At least two conditions

14 (14.4)

At least three conditions

3 (3.1)

Baseline symptom severity

Anxiety $(n=19)$

$9.58 \pm 5.81$

Depression $(n=25)$

$10.64 \pm 5.82$

Alcohol use $(n=14)$

$1.71 \pm 1.94$

Illicit drug use $(n=2)$

$4.5 \pm 6.36$

\begin{tabular}{|c|c|}
\hline \multicolumn{2}{|l|}{ Health Behaviors } \\
\hline \multicolumn{2}{|l|}{ Snacking } \\
\hline Less than 1 time & $47(48.85)$ \\
\hline $1-3$ times & $45(46.4)$ \\
\hline 4 or more times & $5(5.2)$ \\
\hline \multicolumn{2}{|l|}{ Eating fruits and vegetables } \\
\hline 5 or more & $4(4.1)$ \\
\hline 3-4 times & $14(14.4)$ \\
\hline 2 or less & $79(81.4)$ \\
\hline \multicolumn{2}{|l|}{ Sugar drinks } \\
\hline Less than 1 time & $57(58.8)$ \\
\hline 1-3 times & $23(23.7)$ \\
\hline 4 or more times & $16(16.5)$ \\
\hline Smoking tobacco use, yes & $9(9.3)$ \\
\hline Smokeless tobacco use, yes & $1(1.0)$ \\
\hline Snoring, yes & $35(36.1)$ \\
\hline \multicolumn{2}{|l|}{ Napping } \\
\hline Never & $36(37.1)$ \\
\hline Rarely & $16(16.5)$ \\
\hline Sometimes & $25(25.8)$ \\
\hline Often & $10(10.3)$ \\
\hline Always & $9(9.3)$ \\
\hline
\end{tabular}




\begin{tabular}{|c|c|}
\hline Number of exercise days & $3.01 \pm 2.99$ \\
\hline Number of exercise minutes & $31.01 \pm 40.08$ \\
\hline \multicolumn{2}{|l|}{ Binge drinking past 12 months } \\
\hline Never & 87 (89.7) \\
\hline $1-3$ & $7(7.2)$ \\
\hline 4 or more & $3(3.1)$ \\
\hline Drug use past 12 months, yes & $2(2.1)$ \\
\hline \multicolumn{2}{|l|}{ Barriers } \\
\hline Medical care payment, yes & $46(47.4)$ \\
\hline \multicolumn{2}{|l|}{ Transportation access } \\
\hline All the time & $61(62.9)$ \\
\hline Some of the time & $18(18.6)$ \\
\hline Rarely & $9(9.3)$ \\
\hline Never & $8(8.2)$ \\
\hline \multicolumn{2}{|l|}{ Food payment } \\
\hline Often & $13(13.4)$ \\
\hline Sometimes & $27(27.8)$ \\
\hline Never & $56(57.7)$ \\
\hline \multicolumn{2}{|l|}{ Housing security } \\
\hline Very & $8(8.2)$ \\
\hline Somewhat & $3(3.1)$ \\
\hline Not concerned & $85(87.6)$ \\
\hline \multicolumn{2}{|l|}{ Dental care } \\
\hline Less than a year ago & $24(24.7)$ \\
\hline $1-2$ years ago & $16(16.5)$ \\
\hline Greater than 2 years ago & $56(57.7)$ \\
\hline Community safety, yes & $80(82.5)$ \\
\hline Domestic violence, yes & $5(5.2)$ \\
\hline \multicolumn{2}{|l|}{ Living situation } \\
\hline Home/apartment & $79(81.4)$ \\
\hline With a friend or family member & $15(15.5)$ \\
\hline Shelter & $1(1.0)$ \\
\hline Homeless & $2(2.1)$ \\
\hline Access to telephone, yes & $53(54.6)$ \\
\hline
\end{tabular}

Note. Frequencies may add to less than 97 due to missing values.

A total of 22 participants had at least one chronic medical condition. The most common medical condition was hypertension $(n=29 ; 29.9 \%)$, followed by high cholesterol and diabetes. A total of 17 patients $(17.5 \%)$ in our sample had two or more chronic medical conditions and most rated their health as very good (49.5\%) or excellent (19.6\%). Most participants reported snacking once over the past seven days (48.85\%), eating two or less servings of fruits and vegetables per day (81.4\%), and drinking less than one sugary drink per day (58.8\%). A majority reported not using smoking tobacco $(90.7 \%)$ or smokeless tobacco $(99.0 \%)$. Less than a majority reported snoring $(36.1 \%)$ or napping everyday $(9.3 \%)$. Less than a majority reported trouble paying for medical care $(47.4 \%)$, and most reported little trouble with transportation, food payment, and housing security. Most reported receiving dental care more than two years ago (57.7\%) and feeling safe in their community $(82.5 \%)$, while few reported domestic violence (5.2\%). Most lived in a home or an apartment (81.4\%) and had access to a telephone (54.6\%).

\subsection{Relationship with Chronic Health Conditions}

A chi-square test for independence (with Yates' Continuity Correction) indicated no significant association between gender and hypertension, $\left.\chi^{2}(1, \mathrm{n}=97)=.00, p=1.00\right)$, phi, = -.003, gender and cholesterol, $\chi^{2}(1, \mathrm{n}=97)$ 
$=.36, p=.55), p h i,=0.90$, gender and diabetes mellitus, $\left.\chi^{2}(1, \mathrm{n}=97)=.57, p=.45\right)$, phi, $=-.12$, nor gender and multiple chronic conditions, $\left.\chi^{2}(3, \mathrm{n}=97)=.241, p=.971\right)$, phi, $=.050$. There was a moderate, positive correlation between age and number of chronic health conditions, $r=.363, n=97, p<.00$, with higher ages associated with greater numbers of chronic health conditions. There was also a moderate, negative correlation between perceived overall health and number of chronic health conditions, $r=-.368, n=96, p<.00$, with better overall health associated with fewer numbers of chronic health conditions. There were no significant correlations between number of chronic health conditions and employment $(r=.041, p=.698)$, education $(r=.092, p=.371)$, number of unhealthy foods and snacks $(r=-.108, p=.293)$, number of servings of fruits and vegetables $(r=-.037, p=.722)$, access to transportation $(r=-.053, p=.607)$, ability to pay for food $(r=.165, p=.107)$, housing security $(r=.183$, $p=.074)$, dental care $(r=-.170, p=.100)$, nor number of sugary drinks $(r=.182, p=.078)$. There were also no significant correlations between number of chronic health conditions and GAD scores $(r=.395, p=.094)$, PHQ scores $(r=.198, p=.342)$, nor AUDIT scores $(r=.246, p=.397)$.

\section{Discussion}

\subsection{Summary}

A cross-sectional needs assessment of three rural communities in Nicaragua revealed risk factors for CVD that appear to match self-rated health status. Nearly a fourth of participants reported at least one chronic condition and nearly a fifth reported two or more chronic conditions. Hypertension was the most reported condition. Most reported eating fewer than two servings of fruits or vegetables per day, drinking less than one sugary drink per day, snacking infrequently, and consistent exercise. A small percentage reported using harmful substances. Almost half of the sample reported financial or transportation barriers to healthcare. Most participants rated their health as "very good" or better.

\subsection{Interpretation}

The risk factor rates found in this study are consistent with previous research on the prevalence of CVD risk factors in Nicaraguan communities, which have reported 22\% prevalence of hypertension (Valladares et al., 2019) and $8.1 \%$ prevalence of diabetes (PAHO, 2021). In the past, chronic diseases were more prevalent among more affluent communities of society. Today, chronic disease have evolved into an equal opportunity health condition affecting groups across the entire socioeconomic spectrum (Biggs et al., 2010).

In our study, $81.4 \%$ of participants reported eating two or fewer servings of fruits and vegetables per day. In Nicaragua, grains represent approximately $40 \%$ of the national total of calories consumed. Over $95 \%$ of households, both rural and urban, use sugar, salt, and oil six to seven times per week (Food and Agriculture Organization of the United Nations, 2004 [FAO]). Nationally, fats and sugar account for approximately one-quarter of all caloric intake ( $14.75 \%$ and $11.68 \%$, respectively), with slightly higher rates in urban settings $(15.08 \%$ and $11.75 \%$, respectively) and slightly lower rates in rural settings (13.93\% and $11.51 \%$, respectively; 2004). In Nicaragua, salt and oil are used frequently in stable dishes like fried rice and beans; while high quantities of sugar appear often in bottled sodas, coffee, and other drinks.

Among those who smoke tobacco, an inverse relationship exists between lifetime pack years and income status (Lutz et al., 2012). In rural Nicaragua, both cigarettes and alcohol tend to be sold in small quantities and consumed in binges, especially by men. Nationally, tobacco smoking is associated with 30\% of current morbidities (2012). Although government tobacco control policy measures have been initiated, many individuals have a limited understanding of the long-term consequences of tobacco use. Interestingly, we found that most participations in our study did not use tobacco ( 90.7 smoking, 99\% smokeless).

Most rural Nicaraguans have access to health care services and are beginning to use these services for chronic conditions (Food and Agriculture Organization of the United Nations [FAO], 2004). In the past, most patients sought care for acute conditions. Chronic disease-related deaths will likely increase among adults in rural Nicaragua until health care facilities are used as frequently for chronic conditions as they are for acute health problems (Laux, 2012). Yet, barriers to healthcare still exist. For example, about half of the participants in our study reported challenges paying for healthcare services.

In the present study, around ten percent of the participants did not have formal education, another potential risk factor for CVD prevention and incidence. The relationship between poverty and education is not simple. However, education can lead to smarter health decisions for adults and increase the chance for children to develop mentally, physically, and socially (ChildFund, 2019) more fully. Education can also increase the chance for employment and improve overall quality of life and social welfare (Arsani et al., 2020). 


\subsection{Implications}

The results of this cross-sectional study suggest that rates of CVD risk factors in rural Nicaraguan communities are high yet differ by community. Some significant risk factors reported in Latin American communities, such as high rates of tobacco use, alcohol use, and sedentary lifestyles, were not present in the communities included in this study. Moreover, findings support the feasibility and utility of patient-reported outcome measures like the My Own Health Report. The overall good health of these communities reflects the perceived health status reported by participants ("very good" or better). According to the COPC process, once a community has been defined and community health problems have been identified, the next step is to develop and administer interventions with input from the community. The results of this study suggest that community health workers could consider hypertension and diabetes treatment, patient health information on nutrition, healthcare access, and healthy food access as potential target areas to improve community health.

\subsection{Limitations}

The limitations of this study primarily stem from the small and non-representative sample of community residents, making it difficult to establish correlations between outcome variables. The value of this study appears to be the identification of health trends in these three rural communities and the feasibility of using patient-reported outcome measures in rural healthcare delivery. We hesitate to compare our results to other comprehensive studies of rural communities.

\section{Acknowledgements}

The authors would like to acknowledge all collaborators on this project for their significant contributions, including team members and participants.

\section{Competing Interests Statement}

The authors declare that there are no competing or potential conflicts of interest.

\section{References}

Alicea-Planas, J., Greiner, L., \& Greiner, P. A. (2016). Hypertension and related lifestyle factors among persons living in rural Nicaragua. Applied Nursing Research, 29, 43-46. https://doi.org/10.1016/j.apnr.2015.05.010_

Angel-Urdinola, D., Cortez, R., \& Tanabe, K. (2008). Equity, access to health care services and expenditures on health in Nicaragua. Washington, DC: World Bank. Retrieved from https://openknowledge.worldbank.org/bitstream/handle/10986/13667/546290WP0Corte10Box349423B01P UBLIC1.pdf;sequence $=1$

Arsani, A., Ario, B., \& Ramadhan, A. (2020). Impact of Education on Poverty and Health: Evidence from Indonesia. Economics Development Analysis Journal, 9(1), 87-96. https://doi.org/10.15294/edaj.v9i1.34921

Biggs, B., King, L., Basu, S., \& Stuckler, D. (2010). Is wealthier always healthier? The impact of national income level, inequality, and poverty on public health in Latin America. Social science \& medicine, 71(2), 266-273. https://doi.org/10.1016/j.socscimed.2010.04.002_

ChildFund. (2019). Poverty and Education. Retrieved from www.childfund.org/poverty-and-education/

Ducat, L., Philipson, L. H., \& Anderson, B. J. (2014). The mental health comorbidities of diabetes. JAMA, 312(7), 691-692. https://doi.org/10.1001/jama.2014.8040

Fernando, L., Pamela, S., \& Alejandra, L. (2014). Cardiovascular disease in Latin America: the growing epidemic. Progress in cardiovascular diseases, 57(3), 262-267. https://doi.org/10.1016/j.pcad.2014.07.007

Food and Agriculture Organization of the United Nations. (2004). About this one (Organización de las Naciones Unidas para la Alimentación y la Agricultura. Seguridad Alimentaria y Nutricional. Nicaragua. 2004. Retrieved from www.rlc.fao.org/iniciativa/cursos/Curso\%202006/Mod3/9e.pdf [rlc.fao.org].

Glasgow, R. E., Kessler, R. S., Ory, M. G., Roby, D., Gorin, S. S., \& Krist, A. (2014). Conducting rapid, relevant research: lessons learned from the My Own Health Report project. American journal of preventive medicine, 47(2), 212-219. https://doi.org/10.1016/j.amepre.2014.03.007

Global Burden of Disease 2015 Risk Factors Collaborators. (2016). Global, regional, and national comparative risk assessment of 79 behavioral, environmental, and occupational, and metabolic risks or clusters of risks, 1990-2015: a systematic analysis for the Global Burden of Disease Study 2015. Lancet (London, England), 388(10053), 1659. https://www.doi.org/10.1016/S0140-6736(16)31679-8

Gofin, J., \& Gofin, R. (2011). Essentials of global community health. Jones \& Bartlett Learning. 
Greenhalgh, J. (2009). The applications of PROs in clinical practice: What are they, do they work, and why? Quality of Life Research, 18(1), 115-123. https://doi.org/10.1007/s11136-008-9430-6

Instituto Nacional de Estadística. (2003). Características del Departamento de Río San Juan. Rio San Juan, Nicaragua: Instituto Nacional de Estadistica.

Laux, T. S., Bert, P. J., González, M., Unruh, M., Aragon, A., \& Lacourt, C. T. (2012). Prevalence of obesity, tobacco use, and alcohol consumption by socioeconomic status among six communities in Nicaragua. Revista Panamericana de Salud Pública, 32, 217-225. https://doi.org/10.1590/S1020-49892012000900007

Kark, S., \& Kark, E. (1999). Promoting community health: From Pholela to Jerusalem. Witwatersrand University Press.

Lutz, M. A., Lovato, P., \& Cuesta, G. (2012). Cost analysis of varenicline versus bupropion, nicotine replacement therapy, and unaided cessation in Nicaragua. Hospital Practice, 40(1), 35-43. https://doi.org/10.3810/hp.2012.02.946

Ministry of Health. (2007). Marco Conceptual del Modelo de Salud Familiar y Comunitario. Retrieved from: https://www.paho.org/nic/index.php?option=com_docman\&view=download\&category_slug=publicaciones anteriores\&alias $=230$-modelo-de-salud-familiar-y-comunitario\&Itemid=235\#: :text=El $\% 20$ Modelo $\% 20 \mathrm{de}$ \%20Salud $\% 20$ Familiar\%20y\%20Comunitario\%20est $\%$ C3\%A1\%20basado\%20eny $\% 20$ familias $\% 20 \mathrm{de} \% 20$ la\%20comunidad $\% 2 \mathrm{C}$

Pan American Health Organization. (2017). Country report: Nicaragua. Retrieved from: https://www.paho.org/salud-en-las-americas-2017/?p=4286

Pan American Health Organization. (2021). Health in the Americas: Nicaragua. Retrieved from https://www.paho.org/salud-en-las-americas-2017/?p=4286

Pikhart, H., \& Pikhartova, J. (2015). The relationship between psychosocial risk factors and health outcomes of chronic diseases: a review of the evidence for cancer and cardiovascular diseases. WHO Regional Office for Europe.

Prado, A. M., Calderon, D., \& Zúñiga, R. (2016). Providing low-cost and high-quality medications to rural communities in developing countries: The case of Accion Medica Cristiana in Nicaragua. Journal of Business Research, 69(9), 3910-3922. https://doi.org/10.1016/j.jbusres.2015.11.024

United Nations International Children's Emergency Fund (2021, February 21). At a glance: Nicaragua Statistics. Retrieved from https://www.unicef.org/infobycountry/nicaragua_statistics.html\#118

Valladares, M. J., Rodríguez Sándigo, N. A., Rizo Rivera, G. O., Rodríguez Jarquín, M. A., Rivera Castillo, R. M., \& López Bonilla, I. M. (2019). Prevalence, awareness, treatment, and control of hypertension in a small northern town in Nicaragua: The Elieth-HIFARI study. Health science reports, 2(7), e120. https://doi.org/10.1002/hsr2.120

World Health Organization. (2021, February 18). Healthy Diet. Retrieved from https://www.who.int/health-topics/healthy-diet

\section{Copyrights}

Copyright for this article is retained by the author(s), with first publication rights granted to the journal.

This is an open-access article distributed under the terms and conditions of the Creative Commons Attribution license (http://creativecommons.org/licenses/by/4.0/). 